\title{
Oguchi disease
}

INSERM

\section{Source}

INSERM. (1999). Orphanet: an online rare disease and orphan drug data base. Oguchi disease. ORPHA:75382

Oguchi disease is an autosomal recessive retinal disorder characterized by congenital stationary night blindness (see this term) and the Mizuo-Nakamura phenomenon. 